\title{
Pharmaceutical Sales Representatives in the United States and China: The Need for Professional Public Space
}

\section{Xiaoying Chen ${ }^{1}[$}

Accepted: 12 October 2021 / Published online: 11 November 2021

(C) The Author(s), under exclusive licence to Springer Science+Business Media, LLC, part of Springer Nature 2021

\begin{abstract}
Pharmaceutical sales representatives (PSRs) are one of the most frequently used drug information sources for physicians in both the United States and China. During face-to-face interactions, PSRs use various promotional strategies to impact the prescribing behavior. In the United States, PSRs provide physicians small gifts, free drug samples, and "sincere friendships", whereas in China, they played an indispensable role in medical corruption over the past three decades. To cope with the undue influence of PSRs, both these countries have taken positive but insufficient measures to eliminate the effect thus far. By comparing the strategies of American and Chinese PSRs, it was found that building a friendly personal relationship with physicians in a relatively closed private environment (such as physician's office) is a key factor to exert an individualized influence on physicians, even in different social backgrounds and healthcare contexts. Therefore, this essay suggests that it is necessary to limit the establishment of personal relationships and maintain a more professional interaction to reduce the personalized psychological and emotional influences on physicians' professional judgment. To achieve this goal, it is proposed to transfer the physician-PSR interaction to a professional public space as a supplement to current countermeasures and suggestions. The presence of others and the possibility of third party participation will stimulate more ethical and reputational concerns. It is hoped that the increased transparency of the interaction will promote participants to consider more professional norms and mitigate the undue influence of PSRs' individualized strategies.
\end{abstract}

Keywords Promotional strategies · Personal relationships · Prescribing influence Coping measures $\cdot$ Professional public space

Xiaoying Chen

yingseu@126.com

1 School of Humanities, Southeast University, 2 Southeast University Road, Jiangning District, Nanjing 211189, People's Republic of China 


\section{Introduction}

The United States has the highest pharmaceutical spending in the world, approximately 511 billion U.S. dollars in 2019 which is projected to increase to between 605 and 635 billion U.S. dollars in 2024 [72, 73]. China, the world's second-largest national pharmaceutical market [106], has a maximum projected expenditure estimate of 195 billion U.S. dollars for the same year [72]. Pharmaceutical companies spend large amounts of money on promotion annually, with the highest proportion spent on marketing to health care professionals [99]. As a crucial role of the marketing team, pharmaceutical sales representatives (PSRs) have influenced physicians' prescribing behaviors for decades in both the United States and China [21, 24, 47, $83,113,116,120,126]$.

The interaction between PSRs and physicians should be aimed at education and the better use of drugs as PSRs claim to be doing [82] or as their function as defined by the Chinese government [80]. Compared to other information resources like magazines, journals, or websites, one of the advantages of interacting with PSRs is the convenience of acquiring drug information [30, 66, 87, 96, 97]. Physicians do not need to wade through mountains of literature in their busy schedules as research evidence on drugs will be presented to them during the meeting with PSRs, and conversation makes it easier to remember key information [87]. Drug detailing by PSRs is an effective way to spread information especially when new drugs come to market [2], and physicians' questions and needs can be fed back to pharmaceutical companies easily and directly. If the interactions take place within a professional context and physicians can get more accurate and fair information so that their prescribing behavior can be improved, the PSRs' visits would be welcomed [36]. The fact is, however, that PSRs always try to exert undue influence on prescribing by marketing tricks rather than simply providing education and information [33, 93, 94].

As early as 1988, the World Health Organization (WHO) published Ethical Criteria for Medicinal Drug Promotion which aimed at promoting the rational use of medicines [114]. In the last decades, many major pharmaceutical corporations in different countries have developed codes and policies to regulate conflicts of interest, voluntarily committing to ethical business practices and an effective program of internal controls for implementation [108]. Nonetheless, these efforts have not stopped PSRs from using promotional strategies for commercial purposes during their interactions with medical professionals. Then, in different social/cultural backgrounds and healthcare environments in the United States and China, what strategies have PSRs adopted? What influence have they had on prescribing behavior? Are there universal strategies that work in different environments? What are the main current interventions in these two countries? What are the achievements and shortcomings? Are there any other promising measures? This essay will attempt to address these questions by comparing the situation in the United States and China, then put forward a theoretical proposal of a public space for the interaction between physicians and PSRs as a supplement to the current coping measures. 


\section{PSR Promotional Strategies in the United States and China}

\section{Office Visits and Key Opinion Leader (KOL) Making in the United States}

Some studies have shown that conflicts of interest exist in physician-PSR interactions while meeting with PSRs is a part of most American physicians' daily work [83, 24, 93, 54]. PSRs visit physicians' offices frequently with free lunches and small gifts in addition to drug information. Although they are salespersons from pharmaceutical companies, they present themselves as reliable friends to the physicians [33, 10], know their clients' hobbies, interests, or family relationships, talk about "interesting" topics with them during breaks from their busy schedule, share brief moments of pleasure, mentioning the drugs naturally at an appropriate time and in a reasonable way.

Physicians may not consider PSRs as a credible resource of drug information but they are the most frequently used first source [115]. Most physicians reported interactions with PSRs [11, 29], believing that even though their colleagues might be affected by the gifts and promotions [54, 103, 65], they would still be an exception [30, 33, 103, 42]. A study suggested that physicians' confidence was due to psychological dynamics, that is, the relationship with PSRs encouraged them to use a variety of denials and rationalizations to resolve their "cognitive dissonance"( which means they recognize the conflicts of interest but still welcome the interactions) [17]. From another perspective, the influence of PSRs is imperceptible, as small gifts and free lunches are considered out of kindness and friendship rather than a bribe to the physicians. Free drug samples are more ethically acceptable for the sake of patients' interest [83, 65, 23]. PSRs use their carefully designed topics and gifts as a bond to maintain the relationship with physicians, creating a kind of "obligation" to encourage them to respond to their "friendship" through prescriptions [98].

Identifying and seducing the KOL in the medical profession is another common strategy adopted by PSRs. According to the Open Payments Data of the Physician Payments Sunshine Act, the pharmaceutical industry made payments to about 627,000 physicians totaling over 9.35 billion U.S. dollars for speaker and/or consulting fees or for the cumulative value of ownership interests in 2018 [98]. The selected physicians would be paid at least 500 dollars just for one-hour "Lunch and Learn" talks at local physicians" offices, and an additional "honorarium" if they could drive or fly to some other cities [13]. The payments impacted physicians' behaviors especially along with PSRs' psychological tricks. When recruiting KOLs, PSRs will praise the target physician's expertise in the field and their superior competence and reputation as a speaker, express their eagerness in offering the invitation through the attitude and content of the conversation, as well as an impressive payment commitment. Physicians will feel fully respected, valued, and well treated, therefore psychologically satisfied (and uncritical) to an extent. The invitation will become "hard to refuse" [13]. Meanwhile, PSRs will lead the speakers to believe that the purpose of the lectures is to provide useful information and assistance for other physicians to serve more patients [108], 
thereby eliminating the obvious conflict of interest in the invitation and promoting speakers to accept payments more easily without concerns [32]. Before giving a speech, the KOL often does not have enough time and resources to conduct adequate independent research on the drug, therefore the PSRs provide all the information, data, cases, and even the slides required. All of these can seem to be scientifically valid but chosen and framed with marketing goals, the scientific evidence will more likely benefit commercial interests rather than patient interests. $[60,76,102]$.

To KOLs, the interaction with PSRs and the payments impact their professional judgments, as they become the providers of biased information. The fact that KOLs tend to be high prescribers proves that they are always the first "true believers" of their lectures [33]. During the presentation, many KOLs use the strategies with which they were trained by pharmaceutical companies to make themselves more convincing [74]. On the one hand, it is based on a normal psychological expectation that speakers usually want more recognition and agreement. On the other hand, when a KOL receives a payment from the company, an obligation has been created. Protecting the reputation of the drug, as well as their own, has become an underlying duty of the presentation. When faced with doubts from the audience, KOLs will subconsciously defend their point of view through all the favorable evidence they have. For instance, there will always be some adverse effects of new drugs reported for unknown reasons in the first years of use. Before the relationship between these effects and the drug is confirmed, as a professional, physicians should pay more attention to the uncertain risk that may harm their patients and be more cautious about the drug, while as a KOL, they can always find some arguments to defend the continued use of that drug [13]. In other words, during the process of the so-called education, the professionalism of KOLs has been seriously impacted, as they are more on the side of drug companies than patients. Furthermore, for the audience, as the information provider is an expert, the herd mentality and trust in expertise will more or less affect their judgment of the drug [77].

\section{Drug Kickbacks and Personal Gifts/Services in China}

As a way of marketing to professionals, the PSR concept was adopted in China at the end of the 1980s. Before the implementation of the reform and opening-up policy in 1978, China was relatively closed under the planned economy. All medical resources and health service facilities were run entirely by the state and there was a serious shortage of medicines and medical technologies, with few imported drugs for treatment $[49,16]$. After nearly 10 years of economic reform, western drugs and pharmaceutical companies gradually entered the Chinese market. In 1985, Janssen Pharmaceutical set up a joint venture with a local Chinese pharmaceutical company to bring the model of PSR to China for the first time, training the first batch of Chinese PSRs according to the American experience [116]. The emergence of PSRs catered to the huge market demand. They brought advanced western drug information and treatment methods to hospitals and physicians, playing a positive role in education in the first few years [116, 111]. Since the 
1990s, China's pharmaceutical market has grown rapidly, with a sharp increase in the number of both local pharmaceutical companies and PSRs in a short time. The role of PSRs, however, shifted from educators to salespersons.

China is the largest emerging global market, worth more than 1.82 trillion yuan (about 260 billion U.S. dollars) in 2019, an increase of $8.9 \%$ on the previous year [117]. However, there are few brand-name drugs in this market. More than $95 \%$ of the nearly 170,000 published drug batch numbers are generic [63] and more than $90 \%$ of pharmaceutical manufacturers are generic companies [69]. Meanwhile, imported drugs have been introduced very slowly. Of the 291 new molecular entities (NME) approved by the FDA from 2004 to 2014, only 79 successfully entered China until 2017, accounting for less than 30\% of those NMEs [31]. Chinese patients often need to wait more than five years to receive new anti-cancer drugs that have been already on the foreign market [31], with numerous lowquality domestic generic drugs involved in vicious market competition. Without competitive productions, PSRs barely had enough valuable information for physicians during their meetings. Indeed, many PSRs did not even have any medical background, compared with which, marketing skills were more valued when they were hired and trained by pharmaceutical companies [111]. To boost sales, PSRs manipulated prescribing behavior through bribing the physicians $[116,111,128]$.

In China, public hospitals are the most important drug retailers, and drugs prescribed by physicians in public hospitals are often sold directly by their institutions, accounting for $60-70 \%$ of the total pharmaceutical market [72], hence they are the main targets of PSRs. Similar to the United States, Chinese PSRs attempt to build a "friendship" with physicians. They know their families, habits, and preferences, play poker or go bowling with them, even pick up their children from school $[116,120]$. They maintain frequent personal interactions with their clients, often sending greetings to physicians at 7:30 a.m. in the morning and "clock in" at the hospital with breakfast for physicians at 8:00 a.m. At festivals and holidays, PSRs gift physicians concert tickets or top-quality tea in the name of "appreciation for friendship" or "maintaining the relationship". When physicians' children get married, PSRs also attend the weddings with nice gifts [116, 111, 119]. These personal contacts make them emotionally closer, and the establishment of such relationships would not only help PSRs exert psychological influence on physicians, but more importantly, build trust between them, with physicians accepting bribes at the risk of breaking the law without worrying about being sold out by PSRs.

Offering kickbacks has been PSRs' most effective strategy to manipulate prescribing behavior in the past decades. Typically, a 20-30\% kickback is provided to physicians after calculating the number of their prescriptions [112]. A PSR said,

Actually, not providing kickbacks or maintaining the relationships will be $\mathrm{OK}$ if your drug is irreplaceable. But most drugs are facing competition. For example, norfloxacin. There are more than 340 companies producing this medicine in our country. Not much difference in quality between these drugs. Why should the hospitals stock your drug? Why should the physicians prescribe your drug? [116] 
Indeed, this "sales with kickbacks" model is often used not only by small companies without competitive products but also by many large companies. From 2016 to 2019 , more than half of the top 100 pharmaceutical companies in China provided kickbacks directly or indirectly [70].

Recently, under the stricter government regulation, the phenomenon of receiving kickbacks by physicians has been not as common as before but still exists [128, 70]. How PSRs pay bribes have become more subtle and more personal. In the past, PSRs would send gift cards to physicians or make payments for their speaking, consulting, or traveling to conferences in and out of China, whereas now, they convert kickbacks into personal services with economic value. For instance, some PSRs provide physicians with transportation services, pay the bill when physicians entertain their guests, offer assistance when physicians want their children to get into a better school or go abroad, or even hire nannies for their families [119, 70, 20]. A director of a municipal hospital was bribed by selling two properties under his name to a PSR for $64 \%$ and $28 \%$ above market prices. To avoid detection, both properties were registered under the name of a relative of the PSR [18].

The impacts of these marketing strategies on physicians are obvious and clear. There are also imperceptible psychological and emotional influences but stronger economic motivation manipulates physicians' prescriptions more directly. In China, overprescribing and prescribing unnecessary drugs and medical tests are common [62]. A survey showed that about $12 \%$ of doctors prescribed unnecessary diagnostic procedures to a patient to generate profit [64].

\section{PSRs' Choices of Strategy and Physicians' Needs}

In different cultural and institutional environments, American and Chinese PSRs have chosen different strategies for interaction with physicians. The drug detailing is supposed to be all about the drug, but PSRs focused mostly on physicians as individuals, with their behavior and performance designed to meet the different needs and expectations of physicians.

In the United States, physicians have relatively high incomes and social status, value their professional authority and autonomy, and oppose the manipulation of that authority by external forces. Once they realize that their professional judgments have been affected during the interactions with PSRs, they are likely to terminate the "cooperation" [13]. Therefore, trying to manipulate prescriptions directly would be very unwise and the marketing goals of PSRs need to be well disguised. The industry was keenly aware that physicians are feeling overworked, overwhelmed with information and paperwork, and underappreciated [33]. A "feel-good economy" has been created through small gifts, free lunch, respect, and sympathy. Physicians would receive respite and feel understood during the meeting with PSRs, if only for a moment, and that is when they are susceptible to influence $[108,10]$. From the first day of medical school to the last days before retirement, physicians are immersed in this culture [26, 45]. They are used to receiving gifts and payments for conferences or lectures, rationalizing them as an entitlement of their careers [53]. While carefully maintaining physicians' confidence in resisting the influence, PSRs 
are realistically increasing the rate of prescribing $[24,21]$, the number of prescriptions and daily doses [66], the market size [47], etc.

In contrast in China, the situation is different. Most Chinese physicians are managed as individuals in the hospital administrative system and considered more like hospital employees than professionals. In public hospitals, physicians' salaries are mainly determined by hospitals based on their performance assessment (except for a small part set by the government based on their professional titles) [67, 4]. Since physicians' professional labor has not been fully valued [126, 12], the labor fee for diagnosis and treatment is low, so drug sales ${ }^{1}$ have become an important way for physicians and their hospitals to make a profit $[4,7,127]$. Overprescribing behaviors are encouraged by economic incentives [15, 43, 71, 120, 123]. A partnership based on common interests forged [122]. Physicians are more the agents for hospitals rather than for their patients [68]. Even so, the average salary level of physicians is still not high. They are overworked but underpaid, thus, this perverse economic incentive may have directly eroded their ethics [68, 48], and the urgent need to increase income may have crowded out their concerns for other important aspects such as professionalism. Chinese PSRs are very well aware of their clients' difficult positions, so they have not adopted veiled strategies like their American counterparts rather offering bribes to physicians as supplements to their income even in the increasingly strict institutional environment.

Although the strategies of PSRs from the two countries are different, common to both is building and maintaining good personal relationships with physicians is always the first step. Neither inspiring physicians' reciprocity motivations, nor encouraging them to receive bribes can be achieved by simply providing drug information. Often, PSRs fully show their respect, understanding, and sympathy for the physicians personally rather than in general, with all the gifts, free meals and personal topics representing the medium for expressing those feelings. Their relationship would gradually shift from "salesperson/educator/information provider and medical professional" to "friends". After that, more psychological tricks or financial incentives would come into play. Just like a PSR said, "I rely on making a strong personal connection to those docs, something to make me stand out from the crowd." [33]

\footnotetext{
1 In the 1990s, as the economic reform proceeded, Chinese hospitals, as well as enterprises in other industries, began the process of marketization. The government could not afford the rapidly growing medical costs, so partially liberalized the authority of public hospitals' independent management. They were encouraged to finance themselves through the market, and allowed a 15\% drug mark-up. Although this policy was gradually eliminated gradually from 2009, making profit through drug sales is still common in Chinese public hospitals due to inadequate appropriations and rising operating costs.
} 


\section{Main Coping Measures in the United States and China}

\section{Restrictions on Gifts and Disclosure of Payments in the United States}

The conflicts of interest in medical practice have been studied for decades. In the 1950s, Dr. Charles D. May believed that if the industry continued to impose undue influence on the medical profession, the public would soon be up in arms and the more or less "ethical" elements of the industry itself would promote some responsible companies to change their aggressive marketing methods. For a very long time, some people held similar views, but at least so far, they have been proven mistaken $[54,10]$. The public seems to have got used to the fact that physicians have long accepted gifts and payments from industry. People felt it was "less wrong" for physicians to accept gifts from PSRs than it was for judges from lawyers and sports referees from players [41]. Quite a few patients believed that surgeons would make the best choices for their health regardless of financial relationship with industry, and the interactions between surgeons and device manufacturers would improve their care or not be affected [28].

Faced with mounting evidence of PSRs' undue influence, the medical profession and the government have finally realized that they should take the initiative. In 1992, the American Medical Association (AMA) first issued ethics guidelines addressing pharmaceutical marketing and industry gifts [5]. In the addenda "Clarification of Opinion 8.061" adopted by the AMA [6] and the Code on Interactions with Healthcare Professionals published by the Pharmaceutical Research and Manufacturers of America (PhRMA) in 2002 [84], non-educational and practice-related gifts to physicians or those valued at more than 100 U.S. dollars were explicitly forbidden. Over the next few years, several states enacted statutes to further limit industry gifts. For example, Minnesota prohibits gifts with a total annual combined retail value of over 50 dollars since 2006 [34]. In 2009, Massachusetts issued regulations including a ban on all gifts except for modest meals in the provider's practice setting, drug samples, and indirect support for educational programs [85]. However, early evidence suggested that many pharmaceutical companies and physicians did not follow the guidelines [92].

To increase the transparency of the physician-industry relationship, Congress passed "The Physician Payments Sunshine Act" in 2010 as a part of "Affordable Care Act", requiring that detailed information about payments and other "transfers of value" worth over 10 dollars from manufacturers of drugs, medical devices and biologics to physicians and teaching hospitals be disclosed to the public [86]. Data began to be collected in August 2013 and released publicly in September 2014 [90]. Before this regulation, some states had already enacted statutes on the disclosure of payments $[1,25,109]$.

The research on the actual effects of these regulations is not sufficient at present, and the current results are varied. Some studies suggest that even gifts of negligible value and free drug samples, which complied with the regulations, would still have a psychological influence on physicians [24, 30, 54], and there was no evidence that data disclosure has changed the behavior of physicians or 
industry $[61,88]$. In contrast, other studies reported that current policies played an active role in reducing the influence on prescribing behavior [27, 58], but whether these policies affect the quality of care for patients was still unclear $[65,27]$. From the perspective of patients and the public, disclosure of payments affected their trust in physicians $[50,51]$. They supported the disclosure of physician-industry interaction [28], but only a few Americans reported knowing or using the Open Payments website [124, 52].

\section{Government Supervision and Health Policy Adjustment in China}

Different from the regulations in the United States, the Chinese government has taken more strict and direct measures. On the one hand, PSRs' influence on physicians is not subtle but overt, especially as the widespread medical bribery has been beyond the law. On the other hand, compared with professions or individuals, people are more inclined to trust public power and accustomed to counting on the administrative intervention of authority to solve social conflicts. Accordingly, the government participated in the pharmaceutical market as a third party and became the intermediate link between pharmaceutical companies and hospitals.

Since the 1990s, the government has enacted and continuously improved relevant laws and regulations to curb medical corruption, such as the Anti-unfair Competition Law (1993) and Interim Provisions on Anti-commercial bribery (1996), imposing financial and criminal penalties on enterprises and individuals involved, and revoking the licenses of physicians. From 2013 to 2019, over 3000 cases of medical bribery have gone through the judicial adjudication process [20]. For example, in July 2013, GlaxoSmithKline (GSK) was accused of bribing government officials, hospital managers, physicians, and other relevant personnel, with more than twenty people including four senior executives of GSK investigated by the police. It ended in a 489 million U.S. dollars fine, which was the largest corporate fine ever in China [104].

In the past decade, the government has issued more regulations to restrict the interactions between PSRs and physicians, strictly prohibiting any type of transfer of valuable interest. For instance, Beijing [9], Tianjin [107], Hunan [44], and some other provinces require that PSRs should not enter the treatment area in hospitals, and physicians are not allowed to contact PSRs in private. Some hospitals even put up a "No Entrance for PSRs" sign on their gates. In October 2017, the State Council issued a regulation explicitly prohibiting PSRs from marketing drugs to physicians and prohibiting the supply of physicians' prescription data to PSRs or related companies [37]. In 2020, the National Medical Products Administration issued the Regulation on Recording Management of Pharmaceutical Sales Representatives, which further clarified the information transmission and education function of PSRs, and required that PSRs' personal information should be recorded, managed, and disclosed on a government online platform [78].

In addition to laws and regulations, the government has also improved the healthcare environment through the adjustment of health policies to resist medical bribery. Since 2000, China began to implement the centralized drug bidding 
and procurement system in public medical institutions [75]. Specifically, the government selected the highest therapeutic and cost-efficient drugs, and created the National Reimbursement Drug List (NRDL) [101]. Generally, only the drugs on the NRDL are allowed to be prescribed in public hospitals (a very small number of offlist drugs may be prescribed under certain circumstances). Then, the government, instead of hospitals, took the responsibility to negotiate drug prices through bidding and purchase drugs from pharmaceutical companies directly. Hospitals chose the specific drugs they needed from the NRDL and regularly reported those needs to the government. In the last 20 years, this system has been constantly adjusted and improved. Since 2017, the national government has published several policies based on the previous system, including the "two-invoice system" 2 [79] and "4+7 purchase with quantity" 3 [38, 118]. The former aimed to reduce intermediaries between hospitals and pharmaceutical companies, compress the gap between the ex-factory and retail price which agents and PSRs could use to make profits. The latter was to integrate public hospitals' drug demands in exchange for drug price reductions. Only brand-name drugs and domestic generics that have passed consistency evaluations of their quality and efficacy were eligible for bidding. This policy was designed to increase the market share of high-quality drugs and encourage drug research and development by local pharmaceutical companies, which were expected to improve the situation wherein low-quality domestic generics flooded the market and vicious competition was maximized by PSRs through bribery.

The measures above have had positive effects on curbing medical corruption but are not enough. First, these health policies shifted purchasing power from public hospitals to the government, which determined the scope and price of drug procurements. The activity space of PSRs and prescribing rights of physicians have been limited externally, meanwhile, the decrease in drug revenue placed financial strain on hospitals directly, hence, physicians' salaries and supplementary income were cut. These policies not only harmed the vested interests of participants in the short term, but also made no promise of reasonable compensation in the long term and failed to stimulate their internal motivation to restrain their behaviors. Second, although drug procurement is dominated by the government, public hospitals still have the right to decide which specific drugs to purchase. Once a drug gets on the NRDL, the next step is to encourage the hospitals and physicians to procure and prescribe wisely. Hospital managers and physicians are still the primary targets of PSRs. Perhaps because of behavioral inertia, at least so far, there has been no significant change in PSRs' strategies. Third, strict regulations by some local governments that limited PSRs' access to hospitals, or contact with physicians, have not been well

\footnotetext{
2 The policy of "two-invoice system" means only two invoices are allowed in the process of purchasing drugs, that is, one from the manufacturing enterprise to the circulation enterprise and one from the circulation enterprise to the medical institution.

3 The policy of " $4+7$ purchase with quantity" means in four direct-controlled municipalities (Beijing, Tianjin, Shanghai and Chongqing) and seven cities (Shenyang, Dalian, Xiamen, Guangzhou, Shenzhen, Chengdu and Xi'an), the central government would select drugs for pooled procurement from generics that have passed consistency evaluations of the quality and efficacy, trade $60-70 \%$ of the market share of public medical institutions for a reduction in drug prices.
} 
implemented, and the positive effect is currently limited [116, 70]. Nonetheless, if they work well in the future, PSRs as an information channel will also be blocked.

\section{Other Promising Coping Measures}

Given that current measures have not eliminated PSRs' undue influences on prescribing behaviors, more measures should be considered. First, could a radical solution, prohibiting all physician-PSR interactions, be achieved? In the short term, the answer seems to be no. In the United States, drug detailing as a kind of promotion is perfectly legal as long as the information is scientifically accurate and fair and presented appropriately. Commercial speech is protected under the First Amendment of the United States Constitution [55]. While many studies have shown the negative influences of PSRs on prescribing behavior [113, 21, 29], the evidence on the outcomes at the health system level regarding overall costs and quality of care is insufficient [59]. In China, the 2015 revision of the "Classification of Occupations of PRC" first defined the PSR as a formal occupation [35]. This official definition confirmed the legitimacy of PSR as an occupation and justified their interactions with physicians as educators and information providers. Moreover, studies suggested that PSRs played a positive role in information spreading especially when new drugs launched [87, 105]. Without a lengthy and enormous fight against the pharmaceutical industry, it is not likely to impose a complete ban on physician-PSR interactions.

To retain the advantages of interactions and eliminate the negative effects, researchers put forward suggestions from other aspects under the different country backgrounds. In the United States, some researchers argued that current restrictions on gifts from industry are not enough, that all gifts, no matter large or small, should be banned [24, 54, 58, 40]. The contents and methods of payment disclosure should be improved, and more accuracy and transparency are needed [28, 61, 27, 40]. Meanwhile, independent third party organizations should be encouraged as non-commercial and fair sources of drug information [60]. Academic detailing programs supported by the public sector are expected to make sense to promote evidence-based prescribing $[40,81]$. For China, policy reform at the macro level is necessary, including increasing government subsidies to public hospitals, adjusting the physician management system and wage structure, and changing the inappropriate economic incentives [73, 128, 127, 71, 68, 110].

There are also some similar suggestions for both countries, such as emphasizing the importance of education and the self-discipline of professionals. Some studies argue that medical students need to receive sufficient training in recognizing and resisting commercial influences so that they are aware of PSRs' marketing strategies and potential impacts when they become physicians [56, 129]. The medical profession can use valid and reliable practice guidelines to reclaim its independence from industry [40, 22, 121]. In addition, cultivating and encouraging professional virtue should be valued throughout the whole professional career of physicians [3, 14]. A strong culture of independence and incorruptibility within the medical profession should be created, which will lead physicians to feel shame, rather than gratification, when accepting conflicts of interest [93, 94, 89]. These suggestions are important 
and promising in reducing industry impacts and preserving medical professionalism, improving the entire health care environment in the long term.

This essay focuses on physician-PSR interactions at a more specific level. PSRs in the United States and China use different promotion strategies according to physicians' different needs and situations in different social backgrounds but always seek to build a personal relationship with physicians in their interactions. In other words, the establishment of personal relationship is an important factor of the strategies which make undue influences on physicians, even in different contexts. In this case, I argue that adjusting how physician-PSR interact, more precisely, limiting the establishment of a personal relationship, could be helpful to mitigate PSRs' undue influence, as a supplementary measure especially before the effects of long-term measures such as education and virtue cultivation became evident.

\section{A Professional Public Space for Physician-PSR Interaction}

\section{A Theoretical Proposal}

The convenience of drug detailing is mainly due to the "personalized" information being provided, which means the information services are customized according to the needs of physicians. During the interaction, PSRs could respond to physicians' questions, interests, or queries about the drugs in a timely manner. However, the problem is that, except for drug information, PSRs' speaking strategies and psychological tricks are also customized. Physicians often meet with PSRs in their office, which is a relatively closed and private space. In a one-to-one environment, PSRs always try to portray themselves as a "friend" rather than a scheming salesperson $[93,33]$, and bridging the psychological distance with physicians by talking about some designed personal topics, providing small gifts, or having lunch together [91]. As a former PSR stated:

I frame everything as a gesture of friendship. I give them free samples not because it's my job, but because I like them so much. I provide office lunches because visiting them is such a pleasant relief from all the other docs. My drugs rarely get mentioned by me during our dinners. [33]

The "likes" and gifts increase their emotional connection [93], making physicians feel an "obligation" of reciprocity insensibly [54]. In the Chinese context, this closed space once provided an unsupervised "dark room" for briberies.

To protect physician integrity, the type and value of industry gifts are limited in the United States. PSRs are not allowed to express their "likes" excessively. The Physician Payments Sunshine Act requires the disclosure of payments, exposing the benefits exchange between physicians and industry in the "sunshine" to be examined by the public. China has taken a much tougher approach. In some cities, PSRs are only permitted to visit at fixed times and places (such as hospital conference rooms), received by hospital designated personnel, and their conversations must be recorded [107, 100]. The interactions are strictly supervised and managed under such conditions. However, as physicians cannot arrange the 
meeting with PSRs freely according to their own drug information needs, the convenience of this information resource is greatly reduced. My suggestion lies somewhere between these measures, seeking more transparency and openness in their interactions to limit the establishment of a personal relationship while keeping PSRs as a convenient information resource as much as possible.

The physician-PSR interaction should not be a private affair, like chatting with a friend over lunch, but should be treated as a professional activity. I suggest that the interaction in a public space would be helpful to maintain it in the professional field, or to say, a professional public space should be established for their interactions. To be specific, this proposal is to transfer physician-PSR meetings from a private environment to a public space, break the original dual structures of their interaction, expose the interaction process and details, and open the conversation to others. The physician and the PSR are not the only participants, their conversations will be listened to, their actions will be watched, and their interactions will be joined by others. Social psychological research has proved that the presence of others increases physiological arousal on performance [125], creating apprehension about being evaluated [19]. In this open environment, more reputational and ethical concerns will be activated, and instituting personal connections will be difficult.

Goffman claimed that when the individual presents himself before others, people tend to incorporate and exemplify the officially accredited values of the society, choose the way of self-presentation purposefully, and manage their impression in the eyes of others through performance [39]. In the specific scenario of the physicianPSR interaction, the "officially accredited values" undoubtedly include the expectation for physicians, as professionals, to maintain professionalism and resist commercial influences, since the goal of their meeting is supposed to be the better use of drugs and patients' benefit rather than the gifts and free lunch. In this case, it is inappropriate for physicians to interact with PSRs as "friends" or involve too many personal topics in the meeting. To protect the professional image and reputation, physicians will be more motivated to consider more professional norms and avoid conflicts of interest [95]. With this reduction in personal connections, the methods that physicians use to manage their cognitive dissonance, including denying, ignoring, and rationalizing conflicts of interest, may also be weakened, thereby motivating physicians to re-examine their interactions more critically.

For PSRs, they must be more careful with the content and manner of their speech in a public space. On the one hand, different participants may have different standards, and those personal topics designed according to a specific physician's preference may not work as well as before. Except for drug information, PSRs will hardly find an "interesting" topic that can capture all the audience. To avoid being counterproductive, focusing the conversation more on the drugs than physicians as individuals would be a smart move. On the other hand, participants may differ in their attitude toward a specific drug and the degree of familiarity with the drug information. Ambiguous statements are likely to be pursued or cause critical discontent. Exaggerating advantages or covering up weaknesses may lead to a greater risk of loss of trust. The assessment of speaking strategies and benefits appear to be more complex and uncertain than in a private environment. In this situation, the motivation 
to maintain a public image and increasing credibility may stimulate PSRs to adopt more conservative strategies when they are giving speeches.

In summary, I argue that the physician-PSR interaction should occur in a public space that has the following essential characteristics: 1. the environment is open, and any qualified third party who wishes to enter will be allowed; 2 . the information in this space is public and accessible; 3 . benefits are provided openly. Indeed, this proposal is more about the possibility of the transformation of the physician-PSR interaction model at a theoretical level, although my hope is that it could be concretely implemented. Due to an absence of empirical data, we cannot assert that this suggestion will have advantages or disadvantages in terms of economic costs, time costs, information transparency, or the impact on prescribing behavior. Nonetheless, people are always averse to being viewed as biased. With the commitment to put the interests of patients first, physicians have more reason to protect and demonstrate their professional independence to the public. If they truly believe that their interactions with PSRs are appropriate and they are not unduly influenced, then disclosing the interactions in a public space voluntarily rather than hiding in the corner would be helpful to prove their claim and improve public trust.

\section{Diversified Forms and more Possibilities}

To apply this proposal in reality, more concrete forms and detailed rules are needed to be considered to ensure its feasibility and improve its effectiveness. Meanwhile, the support of external conditions is the necessary guarantee to improve physicians' willingness to disclose the interactions in an open space.

The professional public space can be an open physical environment, such as a hospital conference room or a specific area in the public lobby. This will require hospitals to make some adjustments in policy and spatial arrangement, support physicians to meet with PSRs in an open environment, and encourage other relevant professionals to join in. The public space can also be a virtual space, such as multiparty video conferencing or remote interaction platform. Indeed, interacting with physicians electronically is not new as e-detailing occurred as early as 20 years ago [8]. During the COVID-19 pandemic, video conferencing has been more widely used, and e-detailing has been accepted by more health professionals and pharmaceutical companies $[46,57]$. Similar to office visits, current e-detailing is mainly via video conferencing between a physician and a PSR. With the support of technology in the future, if e-detailing can be performed on an open platform and allow other users to join in, this would be a great form to realize the proposal of a professional public space.

Imagine a scene with a physician who is interested in a certain drug but his appointment with the PSR has been canceled due to an emergency. Now he happens to be free in his office, so logs on to the interactive platform to start a conversation with any available PSR online, who may have already contacted him or be someone from another state. He can also skim the ongoing meeting list to find that a respectful specialist is currently meeting with a PSR, so can join in the meeting to listen to the specialist's opinion on the drug. In this way, physicians can interact with PSRs 
and even other physicians remotely in their office, the time of the meetings will be more flexible, and the convenience of face-to-face interaction with PSRs will be also preserved.

In addition to appointments between PSRs and physicians, online or offline interactions can also be organized by hospitals, local medical associations, or other professional institutions, inviting relevant physicians, PSRs from different companies, experts, or scientists to participate. Such interactions may provide physicians with a more reliable information channel than the interaction with a single PSR. The proposal of professional public space does not mean to place barriers for physicians to access drug information from PSRs; rather, the goal is to reduce the influence of non-professional factors and improve the transparency of information through the psychological influence caused by the presence of others in public interactions. Although even in a public space, there is no guarantee that every physicianPSR interaction will involve other participants, as long as the interaction is public, it means that other people may notice or join them at any time. Compared with a physician's office, a relatively open professional environment, where colleagues or patients may appear at any time, is more likely to remind the interactors to be vigilant. While this change in environment cannot eliminate PSRs' individualized influence on physicians, at least they will not be more casual and without scruple than they are in a private place.

In reality, the concrete form of this proposal has more possibilities. More influencing factors and detailed rules should be considered in specific situations, such as how to avoid hidden opinion leaders among participants, especially those biased for some financial reasons from exerting improper impact on others in multi-party interactions.

\section{Conclusion}

Numerous new drugs enter the pharmaceutical market annually, and a slew of scientific research and clinical studies report new evidence on drugs. The pharmaceutical industry sends PSRs directly into physicians' offices to provide the information faceto-face. Except for a few irreplaceable drugs, most PSRs find it difficult to stand out from competitors and rapidly increase the number of prescriptions by simply providing information, hence, marketing strategies aimed at physicians as individuals are widely used.

In different healthcare environments in the United States and China, PSRs try to meet the different needs of physicians through various material and non-material ways. In the past few decades, the manipulation of prescribing behavior by PSRs through bribery was widespread in China. Furthermore, institutional reasons, the understanding of physicians' practice environment, and psychological status were major contributors to sustaining this practice $[116,111,119,70]$.

Currently, both the United States and China have implemented positive policies and regulations to limit PSRs' undue influences on prescribing behavior, but more measures are needed. Unless physicians voluntarily refuse to meet with PSRs or a total ban is imposed by laws and regulations, simply disclosing industry payments 
(as in the United States) or limiting the scope of hospitals' drug procurement and physicians' prescribing (as in China) will be not enough to dispel public doubts about their interactions.

By comparing PSRs' strategies in these two countries, this research essay found that seeking to build a friendly personal relationship is an important step when exerting individualized influence on physicians. If their interactions can be transferred from the current closed private space to a relatively open professional public space, the presence of others and the possibility of more relevant subjects participating may simulate more ethical and reputational concerns, motivating physicians to consider more professional norms and maintain the interaction in a professional field. The restriction on personal relationships will weaken the power of PSRs' psychological tricks. Accepting conflicts of interest as a professional will face a greater ethical challenge than accepting gifts from friends as individuals. Meanwhile, exposing the interaction will also be helpful to increase transparency and public trust.

This proposal is put forward as a competing option to the current "office visit" model at a theoretical level. More studies and further discussions are needed if it is to have a positive effect as expected in reality in the future.

Acknowledgements This article is funded by Postgraduate Research \& Practice Innovation Program of Jiangsu Province (CN) (KYCX18_0207) and China Scholarship Council.

\section{References}

1. AN ACT TO PROMOTE COST CONTAINMENT, TRANSPARENCY AND EFFICIENCY IN THE DELIVERY OF QUALITY HEALTH CARE, Chapter 305 Session Laws of Massachusetts. (2008). https://malegislature.gov/Laws/SessionLaws/Acts/2008/Chapter305. Accessed 16 May 2021.

2. Abdulah, D. M., \& Perot, K. A. (2019). Pharmaceutical promotions and trustworthiness on new drug prescribing among physicians in public general hospitals. Journal of Hospital Administration, $8(6)$.

3. Ahmadi Nasab Emran, S. (2015). An intellectual virtue "vaccination" for physician-pharmaceutical industry interactions. Academic Medicine: Journal of the ASSOCIATION of American Medical Colleges (Chinese Journal), 90(1), 30-32. https://doi.org/10.1097/ACM.0000000000000525

4. Allen, P., Cao, Q., \& Wang, H. (2014). Public hospital autonomy in China in an international context. The International Journal of Health Planning and Management, 29(2), 141-159. https://doi. org/10.1002/hpm. 2200

5. American Medical Association. (2013). Amendment to E-8.061, "Gifts to Physicians from Industry”. https://www.ama-assn.org/sites/ama-assn.org/files/corp/media-browser/public/about-ama/ councils/Council\%20Reports/council-on-ethics-and-judicial-affairs/ceja-2i13.pdf. Accessed 16 May 2021.

6. American Medical Association. (2002). Clarification of opinion 8.061 "Gifts to physicians from industry". Code of Medical Ethics: Current Opinions With Annotations. Chicago, Ill: AMA, 195-203.

7. Barber, S. L., Borowitz, M., Bekedam, H., \& Ma, J. (2014). The hospital of the future in China: China's reform of public hospitals and trends from industrialized countries. Health Policy and Planning, 29(3), 367-378. https://doi.org/10.1093/heapol/czt023

8. Bates, A., Bailey, E., \& Rajyaguru, I. (2002). Navigating the e-detailing maze. Journal of Medical Marketing, 2(3), 255-262.

9. Beijing Municipal Health Commission. (2018). Notice on promoting and standardizing the culture construction and management in healthcare system. http://wjw.beijing.gov.cn/zwgk_20040/fgwj/ wjwfw/201912/t20191219_1301838.html. Accessed 16 May 2021. 
10. Brody, H. (2007). Hooked: Ethics, The Medical Profession, and the Pharmaceutical Industry. Rowman \& Littlefield.

11. Campbell, E. G., Gruen, R. L., Mountford, J., Miller, L. G., Cleary, P. D., \& Blumenthal, D. (2007). A national survey of physician-industry relationships. The New England Journal of Medicine, 356(17), 1742-1750. https://doi.org/10.1056/NEJMsa064508

12. Cao, X. (2014). Submerged discontent and patterns of accommodation: A case study of doctors' pay in two public hospitals in China. The International Journal of Health Planning and Management, 29(2), 124-140.

13. Carlat, D. (2007 Nov 25). Dr. drug rep. New York Times, 25.

14. Chen, X. Y. (2007). Defensive medicine or economically motivated corruption? A Confucian reflection on physician care in China today. The Journal of Medicine and Philosophy, 32(6), 635648. https://doi.org/10.1080/03605310701681021

15. Chen, C., Dong, W., Shen, J. J., Cochran, C., Wang, Y., \& Hao, M. (2014). Is the prescribing behavior of Chinese physicians driven by financial incentives? Social Science \& Medicine, 1982(120), 40-48. https://doi.org/10.1016/j.socscimed.2014.05.033

16. Chen X., Xue S., Lv M., Wang R. (2019) Pharmaceutical Industry in China: Policy, Market and IP. In: Liu KC., Racherla U. (eds) Innovation, Economic Development, and Intellectual Property in India and China. ARCIALA Series on Intellectual Assets and Law in Asia. Springer, Singapore.

17. Chimonas, S., Brennan, T. A., \& Rothman, D. J. (2007). Physicians and drug representatives: Exploring the dynamics of the relationship. Journal of General Internal Medicine, 22(2), 184-190. https://doi.org/10.1007/s11606-006-0041-z

18. China Central Television website. (2020). A star director who had won many awards has been dismissed, which pull out the black interest chain in medical field. http://news.cctv.com/2020/01/15/ ARTIQZrmNffdkAYSzVh0a631200115.shtml. Accessed 12 May 2021.

19. Cottrell, N. B. (1972). Social Facilitation. In C. McClintock (Ed.), Experimental social psychology (pp. 185-236). Holt, Rinehart \& Winston.

20. Dai JB. (2020). Observationl How to govern medical bribery Multiple departments join the investigation on both providers and receivers of bribery. https://www.ccdi.gov.cn/toutiao/202006/t2020 0627_220829.html. Accessed 12 May 2021.

21. Datta, A., \& Dave, D. (2017). Effects of physician-directed pharmaceutical promotion on prescription behaviors: longitudinal evidence. Health Economics, 26(4), 450-468. https://doi.org/10.1002/ hec. 3323

22. Davari, M., Khorasani, E., \& Tigabu, B. M. (2018). Factors influencing prescribing decisions of physicians: A review. Ethiopian Journal of Health Sciences, 28(6), 795-804. https://doi.org/10. 4314/ejhs.v28i6.15

23. De Ferrari, A., Gentille, C., Davalos, L., Huayanay, L., \& Malaga, G. (2014). Attitudes and relationship between physicians and the pharmaceutical industry in a public general hospital in Lima, Peru. PloS one, 9(6), e100114.

24. DeJong, C., Aguilar, T., Tseng, C. W., Lin, G. A., Boscardin, W. J., \& Dudley, R. A. (2016). Pharmaceutical industry-sponsored meals and physician prescribing patterns for medicare beneficiaries. JAMA Internal Medicine, 176(8), 1114-1122. https://doi.org/10.1001/jamainternmed.2016.2765

25. Disclosure of allowable expenditures and gifts by manufacturers of prescribed products, Chapter 091 : Prescription Drug Cost Containment. 18 V.S.A. § 4632 (2008). https://legislature.vermo nt.gov/statutes/section/18/091/04632. Accessed 16 May 2021.

26. Editorial. (2000). Drug company influence on medical education in USA. Lancet, 356(9232), 781.

27. Eisenberg, M. D., Stone, E. M., Pittell, H., \& McGinty, E. E. (2020). The impact of academic medical center policies restricting direct-to-physician marketing on opioid prescribing. Health Affairs (Project Hope), 39(6), 1002-1010. https://doi.org/10.1377/hlthaff.2019.01289

28. Fadlallah, R., Nas, H., Naamani, D., El-Jardali, F., Hammoura, I., Al-Khaled, L., Brax, H., Kahale, L., \& Akl, E. A. (2016). Knowledge, beliefs and attitudes of patients and the general public towards the interactions of physicians with the pharmaceutical and the device industry: A systematic review. PLoS ONE, 11(8), e0160540. https://doi.org/10.1371/journal.pone.0160540

29. Fickweiler, F., Fickweiler, W., \& Urbach, E. (2017). Interactions between physicians and the pharmaceutical industry generally and sales representatives specifically and their association with physicians' attitudes and prescribing habits: A systematic review. British Medical Journal Open, 7(9), e016408. https://doi.org/10.1136/bmjopen-2017-016408

30. Fischer, M. A., Keough, M. E., Baril, J. L., Saccoccio, L., Mazor, K. M., Ladd, E., Von Worley, A., \& Gurwitz, J. H. (2009). Prescribers and pharmaceutical representatives: Why are we 
still meeting? Journal of General Internal Medicine, 24(7), 795-801. https://doi.org/10.1007/ s11606-009-0989-6

31. Fu L. (2017). The new drug approval policy is implemented, and China's pharmaceutical companies are facing opportunities for innovation. Science and Technology Daily, 06.

32. Fugh-Berman, A. (2008). Key opinion leaders: Thus are our medical meetings managed. BMJ, 337(7662), a789. https://doi.org/10.1136/bmj.a789.PMID:18632708;PMCID:PMC2483888

33. Fugh-Berman, A., \& Ahari, S. (2007). Following the script: How drug reps make friends and influence doctors. PLoS Medicine, 4(4), e150. https://doi.org/10.1371/journal.pmed.0040150

34. GIFTS TO PRACTITIONERS PROHIBITED, Minnesota Statutes. $\$ 151.461$ (2006). https://www. revisor.mn.gov/statutes/2006/cite/151.461. Accessed 16 May 2021.

35. Ge LL. (2015). "Pharmaceutical Sales Representative" is included in the national classification of occupations. https://www.cn-healthcare.com/article/20150423/content-472994.html. Accessed 16 May 2021.

36. Gelb, D. J. (2005). The role of the pharmaceutical industry in neurologic education. Neurology, 64(2), E7-E10. https://doi.org/10.1212/01.WNL.0000152729.72672.B7

37. General Office of the CPC Central Committee, General Office of the State Council of PRC. (2017). Notice on deepening reform of the review and approval system and encouraging innovation of drugs and medical devices. http://www.xinhuanet.com//politics/2017-10/09/c_1121775151.htm. Accessed 12 Aug 2019.

38. General Office of the State Council of PRC. (2019). The pilot program of nation organized pooled procurement and use of pharmaceuticals. http://www.gov.cn/zhengce/content/2019-01/17/content_ 5358604.htm. Accessed 12 Aug 2019.

39. Goffman, E. (2008). Behavior in public places. Simon and Schuster.

40. Grande, D. (2010). Limiting the influence of pharmaceutical industry gifts on physicians: Self-regulation or government intervention? Journal of General Internal Medicine, 25(1), 79-83. https:// doi.org/10.1007/s11606-009-1016-7

41. Green, M. J., Masters, R., James, B., Simmons, B., \& Lehman, E. (2012). Do gifts from the pharmaceutical industry affect trust in physicians? Family Medicine, 44(5), 325-331.

42. Halperin, E. C., Hutchison, P., \& Barrier Jr, R. C. (2004). A population-based study of the prevalence and influence of gifts to radiation oncologists from pharmaceutical companies and medical equipment manufacturers. International Journal of Radiation Oncology* Biology* Physics, 59(5), 1477-1483.

43. He, A. J., \& Qian, J. (2016). Explaining medical disputes in Chinese public hospitals: The doctorpatient relationship and its implications for health policy reforms. Health Economics, Policy, and Law, 11(4), 359-378. https://doi.org/10.1017/S1744133116000128

44. Health Commission of Hunan Province. (2016). Notice on further rectification of key climate problem in healthcare system. http://wjw.hunan.gov.cn/xxgk/tzgg/201612/t20161229_4020834.html. Accessed 16 May 2021.

45. Hodges, B. (1995). Interactions with the pharmaceutical industry: experiences and attitudes of psychiatry residents, interns and clerks. CMAJ: Canadian Medical Association Journal, 153(5), 553.

46. Hoffman, J. D., Shayegani, R., Spoutz, P. M., Hillman, A. D., Smith, J. P., Wells, D. L., Popish, S. J., Himstreet, J. E., Manning, J. M., Bounthavong, M., \& Christopher, M. (2020). Virtual academic detailing (e-Detailing): A vital tool during the COVID-19 pandemic. Journal of the American Pharmacists Association: JAPhA, 60(6), e95-e99. https://doi.org/10.1016/j.japh.2020.06.028

47. Hollands, S. (2020). Receipt of promotional payments at the individual and physician network level associated with higher branded antipsychotic prescribing rates. Administration and Policy in Mental Health, 47(1), 73-85. https://doi.org/10.1007/s10488-019-00974-7

48. Hsiao, W. C. (2007). The political economy of Chinese health reform. Health Economics, Policy, and Law, 2(Pt 3), 241-249. https://doi.org/10.1017/S1744133107004197

49. Hu, R., Zou, H., Shen, C., \& Heng, F. (2011). Health care system reform in China: Issues, challenges and options. China Economics and Management Academy, Central University of Finance and Economics.

50. Hwong, A. R., Sah, S., \& Lehmann, L. S. (2017). The effects of public disclosure of industry payments to physicians on patient trust: A randomized experiment. Journal of General Internal Medicine, 32(11), 1186-1192. https://doi.org/10.1007/s11606-017-4122-y

51. Kanter, G. P., Carpenter, D., Lehmann, L. S., \& Mello, M. M. (2019). US nationwide disclosure of industry payments and public trust in physicians. JAMA Network Open, 2(4), e191947. https://doi. org/10.1001/jamanetworkopen.2019.1947 
52. Kanter, G. P., Carpenter, D., Lehmann, L., \& Mello, M. M. (2019). Effect of the public disclosure of industry payments information on patients: Results from a population-based natural experiment. British Medical Journal Open, 9(2), e024020. https://doi.org/10.1136/bmjopen-2018-024020

53. Kassirer, J. P. (2000). Financial indigestion. JAMA, 284(17), 2156-2157.

54. Katz, D., Caplan, A. L., \& Merz, J. F. (2010). All gifts large and small: Toward an understanding of the ethics of pharmaceutical industry gift-giving. The American Journal of Bioethics: AJOB, 10(10), 11-17. https://doi.org/10.1080/15265161.2010.519226

55. Kesselheim, A. S., \& Avorn, J. (2008). Pharmaceutical promotion to physicians and First Amendment rights. The New England Journal of Medicine, 358(16), 1727-1732. https://doi.org/10.1056/ NEJMsb0708920

56. Keys, T., Ryan, M. H., Dobie, S., Satin, D., \& Evans, D. V. (2019). Premedical student exposure to pharmaceutical marketing: Too much, too soon?. Family Medicine, 51(9), 722-727. https://doi.org/ 10.22454/FamMed.2019.360469

57. Khan, M. M. R., \& Basak, K. (2021). Shifts in Pharma-Marketing Trends in Post COVID-19 Era. International Journal of Multidisciplinary: Applied Business and Education Research, 2(2), $108-114$.

58. King, M., \& Bearman, P. S. (2017). Gifts and influence: Conflict of interest policies and prescribing of psychotropic medications in the United States. Social Science \& Medicine, 1982(172), 153162. https://doi.org/10.1016/j.socscimed.2016.11.010

59. Latten, T., Westra, D., Angeli, F., Paulus, A., Struss, M., \& Ruwaard, D. (2018). Pharmaceutical companies and healthcare providers: Going beyond the gift - An explorative review. PLoS ONE, 13(2), e0191856. https://doi.org/10.1371/journal.pone.0191856

60. Leonardo Alves, T., Lexchin, J., \& Mintzes, B. (2019). Medicines information and the regulation of the promotion of pharmaceuticals. Science and Engineering Ethics, 25(4), 1167-1192. https:// doi.org/10.1007/s11948-018-0041-5

61. Lexchin, J., \& Fugh-Berman, A. (2021). A ray of sunshine: transparency in physician-industry relationships is not enough. Journal of General Internal Medicine. https://doi.org/10.1007/ s11606-021-06657-0

62. Li, Y., Xu, J., Wang, F., Wang, B., Liu, L., Hou, W., \& Lu, Z. (2012). Overprescribing in China, driven by financial incentives, results in very high use of antibiotics, injections, and corticosteroids. Health Affairs, 31(5), 1075-1082.

63. Li HM. (2018). Eliminate the "pain points" of using medicines for patients. http://www.gov.cn/ zhengce/2018-04/13/content_5282106.htm. Accessed 12 May 2021.

64. Liang, Z., Xu, M., Liu, G., Zhou, Y., \& Howard, P. F. (2020). Doctors in Chinese public hospitals: Demonstration of their professional identities. BMC Medical Education, 20(1), 501. https://doi.org/ 10.1186/s12909-020-02339-3

65. Lieb, K., \& Brandtönies, S. (2010). A survey of german physicians in private practice about contacts with pharmaceutical sales representatives. Deutsches Arzteblatt International, 107(22), 392398. https://doi.org/10.3238/arztebl.2010.0392

66. Lieb, K., \& Scheurich, A. (2014). Contact between doctors and the pharmaceutical industry, their perceptions, and the effects on prescribing habits. PLOS ONE, 9(10), e110130. https://doi.org/10. 1371/journal.pone.0110130

67. Liu, X., \& Mills, A. (2005). The effect of performance-related pay of hospital doctors on hospital behaviour: A case study from Shandong China. Human Resources for Health, 3, 11. https://doi.org/ 10.1186/1478-4491-3-11

68. Liu, Y., \& Saltman, R. B. (2019). Establishing Appropriate Agency Relationships for Providers in China. Inquiry: A Journal of Medical Care Organization, Provision and Financing, 56, 46958019872348. https://doi.org/10.1177/0046958019872348

69. Ma X. (2018). The replacement of imported drugs by generic drugs is accelerated, and high-quality drugs are included in social medical insurance. https://www.yicai.com/news/5413267.html. Accessed 12 Aug 2018.

70. Ma XY., Zhao Y., Song YZ. (2021). An in-depth investigation on the phenomenon of kickbacks receiving by physicians: hard to forbid in many places and new high-end drug are at the top of the list. http://www.xinhuanet.com/politics/2021-04/14/c_1127330136.htm. Accessed 12 May 2021.

71. Mao, W., Tang, S., \& Chen, W. (2013). Does perverse economic incentive lead to the irrational uses of medicines? Expert Review of Pharmacoeconomics \& Outcomes Research, 13(6), 693-696. https://doi.org/10.1586/14737167.2013.856266 
72. Mikulic, M. (2020). Total nominal spending on medicines in the U.S. from 2002 to 2019. https:// www.statista.com/statistics/238689/us-total-expenditure-on-medicine/\#statisticContainer. Accessed 12 May 2021.

73. Mikulic, M. (2021). Projected global pharmaceutical sales for 2024, by region. https://www.stati sta.com/statistics/299694/world-pharmaceutical-sales-by-region-forecast/. Accessed 12 May 2021.

74. Millard, W. B. (2008). Dispatch from the pharmasphere: An industry's fault lines on display. Annals of Emergency Medicine, 51(2), 175-180. https://doi.org/10.1016/j.annemergmed.2007.12. 009

75. Ministry of Health of PRC. (2001). Notice on Issuance of "Standards for the centralized drug bidding and procurement in public medical institutions (Trial)". http://www.gov.cn/gongbao/content/ 2002/content_61499.htm. Accessed 16 May 2021.

76. Moynihan, R. (2008). Key opinion leaders: Independent experts or drug representatives in disguise? BMJ (Clinical research ed.), 336(7658), 1402-1403. https://doi.org/10.1136/bmj.39575. 675787.651

77. Nair, H. S., Manchanda, P., \& Bhatia, T. (2010). Asymmetric social interactions in physician prescription behavior: The role of opinion leaders. Journal of Marketing Research, 47(5), 883-895. https://doi.org/10.1509/jmkr.47.5.883

78. National Medical Products Administration. (2020). Announcement on the Regulation on Recording Management of Pharmaceutical Sales Representatives (No. 105 of 2020). https://www.nmpa. gov.cn/xxgk/ggtg/qtggtg/20200930163955170.html. Accessed 16 May 2021.

79. National Medical Products Administration of PRC. (2016). Notice on the implementation of the "two-invoice system" (trial) for drug procurement in public medical institutions. http://www.nmpa. gov.cn/WS04/CL2196/324173.html. Accessed 12 Aug 2019.

80. National Medical Products Administration. (2020). Measures for the Administration of the Record of Medical Representatives (Trial). https://www.nmpa.gov.cn/xxgk/ggtg/qtggtg/202009301639551 70.html. Accessed 12 May 2021.

81. Ndefo, U. A., Norman, R., \& Henry, A. (2017). Academic detailing has a positive effect on prescribing and decreasing prescription drug costs: a health plan's perspective. American Health \& Drug Benefits, 10(3), 129-133.

82. O’Donnell, M. J., Molloy, D. W., Smith, S. D., Dubois, S., \& Russo, R. M. (2004). The selfperceived role and educational needs of pharmaceutical representatives: A survey. Education for health (Abingdon, England), 17(3), 339-345. https://doi.org/10.1080/13576280400002544

83. Patwardhan, A. R. (2016). Physicians-pharmaceutical sales representatives interactions and conflict of interest: Challenges and solutions. Inquiry: A journal of medical care organization, provision and financing, 53, 0046958016667597. https://doi.org/10.1177/0046958016667597

84. Pharmaceutical Research and Manufacturers of America (PhRMA). (2009). Code on Interactions with Healthcare Professionals: Principles \& Practice. PhRMA. https://www.phrma.org/codesand-guidelines/code-on-interactions-with-health-care-professionals. Accessed 12 Aug 2019.

85. Pharmaceutical and medical device manufacturer conduct, Code of Massachusetts Regulations (CMR) . 105 CMR 970.00 (2009). https://www.mass.gov/law-library/105-cmr. Accessed 16 May 2021.

86. Physician Payments Sunshine Act - Open Payments. (2015). https://www.hopkinsmedicine.org/ research/resources/offices-policies/OPC/Policies_Regulations/sunshine_act.html. Accessed 16 May 2021.

87. Prosser, H., \& Walley, T. (2003). Understanding why GPs see pharmaceutical representatives: A qualitative interview study. The British Journal of General Practice : The Journal of the Royal College of General Practitioners, 53(489), 305-311.

88. Rachal M., Lim D. (2019). Sunlight doesn't dent industry funding to doctors over half-decade. MedTech Dive [Internet]. https://www.medtechdive.com/news/sunlight-doesnt-dent-industry-fundi ng-to-doctors-over-half-decade/568228/. Accessed 16 May 2021.

89. Research Group on Conflicts of Interest, Chinese and American Medical Professionalism Research Center, the School of Health Humanities, Peking University. (2016). Management strategies for conflicts of interest in medical practices. President of Chinese Hospital, 000(015), 72-75.

90. Richardson E. (2014). The Physician Payments Sunshine Act. https://www.healthaffairs.org/ do/https://doi.org/10.1377/hpb20141002.272302/full/. Accessed 16 May 2021.

91. Rim, S., Min, K. E., Liu, P. J., Chartrand, T. L., \& Trope, Y. (2019). The gift of psychological closeness: how feasible versus desirable gifts reduce psychological distance to the giver. Personality \& Social Psychology Bulletin, 45(3), 360-371. https://doi.org/10.1177/0146167218784899 
92. Ross, J. S., Lackner, J. E., Lurie, P., Gross, C. P., Wolfe, S., \& Krumholz, H. M. (2007). Pharmaceutical company payments to physicians: Early experiences with disclosure laws in Vermont and Minnesota. JAMA, 297(11), 1216-1223. https://doi.org/10.1001/jama.297.11.1216

93. Sah, S. (2012). Conflicts of interest and your physician: Psychological processes that cause unexpected changes in behavior. The Journal of Law, Medicine \& ethics : A Journal of the American Society of Law, Medicine \& Ethics, 40(3), 482-487. https://doi.org/10.1111/j.1748-720X.2012. 00680.x

94. Sah, S., \& Fugh-Berman, A. (2013). Physicians under the influence: Social psychology and industry marketing strategies. The Journal of Law, Medicine \& Ethics : A Journal of the American Society of Law, Medicine \& Ethics, 41(3), 665-672. https://doi.org/10.1111/jlme.12076

95. Sah, S., \& Loewenstein, G. (2014). Nothing to declare: Mandatory and voluntary disclosure leads advisors to avoid conflicts of interest. Psychological Science, 25(2), 575-584. https://doi.org/10. $1177 / 0956797613511824$

96. Saito, S., Mukohara, K., \& Bito, S. (2010). Japanese practicing physicians' relationships with pharmaceutical representatives: A national survey. PLOS ONE, 5(8), e12193. https://doi.org/10.1371/ journal.pone.0012193

97. Salmasi, S., Ming, L. C., \& Khan, T. M. (2016). Interaction and medical inducement between pharmaceutical representatives and physicians: A meta-synthesis. Journal of Pharmaceutical Policy and Practice, 9, 37. https://doi.org/10.1186/s40545-016-0089-z

98. Scher, J. U., \& Schett, G. (2021). Key opinion leaders - a critical perspective. Nature Reviews. Rheumatology, 17(2), 119-124. https://doi.org/10.1038/s41584-020-00539-1

99. Schwartz, L. M., \& Woloshin, S. (2019). Medical marketing in the United States, 1997-2016. JAMA, 321(1), 80-96. https://doi.org/10.1001/jama.2018.19320

100. Shanghai Municipal Health Commission. (2017). The opinion on the construction of pharmaceutical products kickback management system. http://wsjkw.sh.gov.cn/ygwj/20180525/0012-30948. html. Accessed 16 May 2021.

101. Shi, J., Liu, R., Jiang, H., Wang, C., Xiao, Y., Liu, N., Wang, Z., \& Shi, L. (2018). Moving towards a better path? A mixed-method examination of China's reforms to remedy medical corruption from pharmaceutical firms. British Medical Journal Open, 8(2), e018513. https://doi.org/10.1136/bmjop en-2017-018513

102. Sismondo S. (2015). How to make opinion leaders and influence people. CMAJ: Canadian Medical Association journal = journal de l'Association medicale canadienne, 187(10), 759-760. Advance online publication. https://doi.org/10.1503/cmaj.150032

103. Steinman, M. A., Shlipak, M. G., \& McPhee, S. J. (2001). Of principles and pens: Attitudes and practices of medicine housestaff toward pharmaceutical industry promotions. The American Journal of Medicine, 110(7), 551-557.

104. Sullivan T. (2014). GSK Chinese bribery scandal ends in $\$ 489$ million fine, executive sentenced. https://www.policymed.com/2014/09/gsk-chinese-bribery-scandal-ends-in-489-million-fine-execu tive-sentenced.html. Accessed 12 Aug 2019.

105. Søndergaard, J., Vach, K., Kragstrup, J., \& Andersen, M. (2009). Impact of pharmaceutical representative visits on GPs' drug preferences. Family Practice, 26(3), 204-209. https://doi.org/10. 1093/fampra/cmp010

106. Tan H. (2018). China's pharmaceutical industry is poised for major growth. https://www.cnbc.com/ 2018/04/19/chinas-pharmaceutical-industry-is-poised-for-major-growth.html. Accessed 12 Aug 2019.

107. Tianjin Municipal Health Commission. (2018). Interim procedures in receiving representatives of pharmaceutical enterprises by Tianjin Medical and health institutions. http://wsjk.tj.gov.cn/ ZWGK3158/ZCFG6243_1/GZWJ625/202011/t20201110_4050358.html. Accessed 16 May 2021.

108. Villalba, L. (2019). Pharmaceutical companies and medical practitioners or "the beast and the beauty"? Clinics in Dermatology, 37(1), 16-20. https://doi.org/10.1016/j.clindermatol.2018.09.005

109. WHOLESALE DRUG DISTRIBUTOR LICENSING REQUIREMENTS, Minnesota Statutes. $\$ 151.47$ (2006). https://www.revisor.mn.gov/statutes/cite/151.461. Accessed 16 May 2021.

110. Wang, Y., Zhu, Y., Liu, X., Xu, X., Fang, W., \& Li, X. (2020). The effects of county public hospital reform on the consumption and costs of antibiotics: evidence from a quasinatural experiment in Jiangsu China. BioMed Research International, 2020, 9262170. https://doi.org/10.1155/2020/ 9262170

111. Wang Z'A. (2016). The growth and evolution of pharmaceutical representatives in China. http:// yao.dxy.cn/article/513112. Accessed 12 May 2021. 
112. Wang M, Cao Z. (2013). All 73 hospitals in Zhangzhou, Fujian Province are involved in medical corruption; how much does medical corruption drive up drug prices?. China Youth Daily, 03.

113. Wood, S. F., Podrasky, J., McMonagle, M. A., Raveendran, J., Bysshe, T., Hogenmiller, A., \& Fugh-Berman, A. (2017). Influence of pharmaceutical marketing on Medicare prescriptions in the District of Columbia. PloS one, 12(10), e0186060.

114. World Health Organization. (1988). Ethical criteria for medicinal drug promotion. World Health Organization. https://apps.who.int/iris/handle/10665/38125. Accessed 12 May 2021

115. World Health Organization. (2005). Drug promotion : what we know, what we have yet to learn : reviews of materials in the WHO/HAI database on drug promotion / Pauline Norris ... [et al.]. World Health Organization. https://apps.who.int/iris/handle/10665/69177. Accessed 12 May 2021

116. Wu H., Chen HW. (2013). Pharmaceutical sales representatives' roadmap of bribery: the main target are attending doctors. Law and News, 11. Available on: http://news.sina.com.cn/c/sd/2013-1213/110128975996.shtml. Accessed 12 May 2021.

117. Xinhua Net. (2020). China's pharmaceutical market will show a rare negative growth this year, innovative drugs ignite the engine of future growth. http://www.xinhuanet.com/health/2020-08/ 13/c_1126364146.htm. Accessed 12 May 2021.

118. Xu W. (2019) Remedies to reduce drug prices. China Daily. http://english.gov.cn/news/policy_ briefings/2019/01/18/content_281476483983906.htm. Accessed 12 Aug 2019.

119. Xu TT., Wang ZY., Wang Z. (2019). The medical bribery case. Health times Newspaper, (03). Available on: http://paper.people.com.cn/jksb/html/2019-09/03/content_1945443.htm. Accessed 12 May 2021.

120. Yang, W. (2016). How does the pharmaceutical industry influence prescription? A qualitative study of provider payment incentives and drug remunerations in hospitals in Shanghai. Health Economics, Policy, and Law, 11(4), 379-395. https://doi.org/10.1017/S1744133116000086

121. Yang, Z., \& Fan, D. (2012). How to solve the crisis behind Bribegate for Chinese doctors. Lancet (London, England), 379(9812), e13-e15. https://doi.org/10.1016/S0140-6736(11)60137-2

122. Yip, W. C., Hsiao, W. C., Chen, W., Hu, S., Ma, J., \& Maynard, A. (2012). Early appraisal of China's huge and complex health-care reforms. Lancet (London, England), 379(9818), 833-842. https://doi.org/10.1016/S0140-6736(11)61880-1

123. Yip, W. C., Hsiao, W., Meng, Q., Chen, W., \& Sun, X. (2010). Realignment of incentives for health-care providers in China. Lancet (London, England), 375(9720), 1120-1130. https://doi.org/ 10.1016/S0140-6736(10)60063-3

124. Young, P. D., Xie, D., \& Schmidt, H. (2018). Towards patient-centered conflicts of interest policy. International Journal of Health Policy and Management, 7(2), 112-119. https://doi.org/10. 15171/ijhpm.2017.128

125. Zajonc, R. B. (1965). Social facilitation. Science, 149(3681), 269-274.

126. Zhang, W., \& Grouse, L. (2013). Physician bribes in the US and China. Journal of Thoracic Disease, 5(5), 711-715. https://doi.org/10.3978/j.issn.2072-1439.2013.10.03

127. Zhang, X., Lai, H., Zhang, L., He, J., Fu, B., \& Jin, C. (2020). The impacts and unintended consequences of the nationwide pricing reform for drugs and medical services in the urban public hospitals in China. BMC Health Services Research, 20(1), 1058. https://doi.org/10.1186/ s12913-020-05849-4

128. Zhang, Y., Yu, Y. S., Tang, Z. H., Chen, X. H., \& Zang, G. Q. (2014). Crack down on medical corruption: An urgent matter in China. European Journal of Internal Medicine, 25(1), e2-e3. https:// doi.org/10.1016/j.ejim.2013.10.012

129. Zhu, W., Wang, L., \& Yang, C. (2018). Corruption or professional dignity: An ethical examination of the phenomenon of "red envelopes" (monetary gifts) in medical practice in China. Developing World Bioethics, 18(1), 37-44. https://doi.org/10.1111/dewb.12152

Publisher's Note Springer Nature remains neutral with regard to jurisdictional claims in published maps and institutional affiliations. 